\title{
Profil Persalinan dengan Plasenta Previa di RSUP Prof. Dr. R. D. Kandou Manado periode 1 Januari 2015 - 31 Desember 2015
}

\author{
${ }^{1}$ Alif A. Pawa \\ ${ }^{2}$ Maya Mewengkang \\ ${ }^{2}$ Erna Suparman
}

\author{
${ }^{1}$ Kandidat Skripsi Fakultas Kedokteran Universitas Sam Ratulangi Manado \\ ${ }^{2}$ Bagian Obstetri-Ginekologi Fakultas Kedokteran Universitas Sam Ratulangi Manado \\ Email: alifpawa@gmail.com
}

\begin{abstract}
Placenta previa is a complication of pregnancy in which the placenta is located at the bottom of the uterus, partially or completely covering the cervix. This causes painless vaginal bleeding and some leads to bleeding. The bleeding may be intense enough to threaten mother's life leading to labor immediately, either elective or emergency. This study was aimed to obtain the profile of labor with placenta previa at Prof. Dr. R. D. Kandou Hospital Manado period 1 January 2015-31 December 2015. The results showed that of 27 cases, the most incidents were in the age group more than equal with 35 years $(48.1 \%)$. The most parity was 2-4 (74.1\%). The incidence of placenta previa with SC history was $25.9 \%$. Based on types of the management, the highest was placenta previa that got expectative management $(63 \%)$. Based on the classification, total placenta previa amounted to $88.9 \%$. Based on gestational age, aterm was $55.6 \%$. All labors with placenta previa used SCTP. The most indication of labor was inpartu (96.3\%). The most labor complication was pre eclampsia (11.1\%). Most of the babies were born alive (96.3\%). Conclusion: Women who had placenta previa symptoms like bleeding without pain had to be immediately checked into hospitals or Obstetrics and Gynecology specialists to get the optimum management as soon as possible.
\end{abstract}

Keywords: placenta previa, labor

\begin{abstract}
Abstrak: Plasenta previa adalah komplikasi kehamilan di mana plasenta terletak di bagian bawah rahim, sebagian atau seluruhnya menutupi leher rahim. Hal ini menyebabkan perdarahan vagina tanpa rasa sakit dan beberapa mengarah ke perdarahan. Perdarahan yang mungkin cukup besar untuk mengancam kehidupan ibu janin membuat persalinan segera, baik secara elektif maupun darurat. Penelitian ini bertujuan untuk mengetahui gambaran persalinan dengan plasenta previa di RSUP Prof. Dr. R. D. Kandou Manado periode 1 Januari 2015 - 31 Desember 2015. Hasil penelitian mendapatkan dari 27 kasus, didapatkan insiden terbanyak pada kelompok usia lebih dari dan sama dengan 35 tahun sebanyak 48,1\% kasus. Paritas terbanyak ialah paritas $2-4$ sebanyak $74,1 \%$. Kejadian plasenta previa dengan riwayat SC sebanyak 25,9\%. Berdasarkan jenis tatalaksana, terbanyak pada plasenta previa yang mendapatkan tatalaksana ekspektatif sebanyak 63\%. Berdasarkan klasifikasi, plasenta previa totalis sebanyak $88,9 \%$. Berdasarkan usia kehamilan, aterm sebanyak 55,6\%. Semua persalinan pada plasenta previa menggunakan cara SCTP. Indikasi persalinan terbanyak ialah inpartu sebanyak 96,3\%. Penyulit persalinan terbanyak ialah preeklampsia dengan $11,1 \%$. Luaran bayi terbanyak ialah lahir hidup sebanyak 96,3\%. Simpulan: Wanita yang memiliki gejala plasenta previa seperti perdarahan tanpa nyeri harus segera memeriksakan ke rumah sakit atau dokter spesialis Obstetri dan Ginekologi untuk mendapatkan penanganan optimal sesegera mungkin.
\end{abstract}

Kata kunci: plasenta previa, persalinan 
Kehamilan adalah peristiwa alamiah dan merupakan hal yang sangat didambakan oleh setiap wanita, karena seorang wanita baru akan merasa menjadi wanita yang sempurna saat dirinya mendapatkan kehamilan hingga akhirnya melahirkan. Akan tetapi, setiap kehamilan tetap perlu perhatian khusus karena mungkin akan memiliki resiko bagi ibu maupun janin yang dikandungnya. ${ }^{1-3}$

Perdarahan obstetrik yang terjadi pada kehamilan trimester ketiga perdarahan obstetrik yang terjadi pada kehamilan trimester ketiga dan yang terjadi setelah anak atau plasenta lahir pada umumnya adalah perdarahan yang berat, dan jika tidak mendapat penanganan yang cepat bisa mendatangkan syok yang fatal. Salah satu sebabnya adalah plasenta previa. ${ }^{4}$

Plasenta previa adalah komplikasi kehamilan di mana plasenta terletak di bagian bawah rahim, sebagian atau seluruhnya menutupi leher rahim. Hal ini menyebabkan perdarahan vagina tanpa rasa sakit dan beberapa mengarah ke perdarahan. Perdarahan yang mungkin cukup besar untuk mengancam kehidupan ibu janin membuat persalinan segera, baik secara elektif atau darurat. ${ }^{5}$

Plasenta previa telah diklasifikasikan oleh tingkat perambahan pada os. servikal internal. Dalam plasenta previa, perdarahan lebih mungkin terjadi selama trimester ketiga, sebagai konsekuensi dari perkembangan segmen bawah rahim dan pelebaran leher rahim yang disebabkan oleh kontraksi uterus, pemeriksaan vagina juga dapat menyebabkan perdarahan antepartum. Faktor risiko untuk pengembangan plasenta previa termasuk pengiriman sebelum seksio sesarea, terminasi kehamilan, operasi intrauterine, merokok, kehamilan multifetal, peningkatan paritas, usia ibu dan peningkatan tingkat seksio caesar. Plasenta previa berhubungan dengan konsekuensi yang merugikan bagi ibu dan anak, seperti Intra-Uterine Growth Restriction (IUGR), kelahiran prematur, antenatal dan intrapartum perdarahan, transfusi darah ibu dan histerektomi darurat. ${ }^{6}$

Penelitian ini bertujuan untuk mendapatkan gambaran persalinan dengan plasenta previa di RSUP Prof. Dr. R. D. Kandou Manado periode 1 Januari 2015 31 Desember 2015.

\section{METODE PENELITIAN}

Penelitian ini menggunakan metode penelitian deskriptif retrospektif. Sampel diambil dari data rekam medik di Instalasi Rekam Medik RSUP Prof. Dr. R. D. Kandou Manado, kemudian data diolah berdasarkan variabel yang diteliti.

\section{HASIL PENELITIAN}

Dari hasil penilitian retrospektif deskriptif yang dilakukan, didapatkan jumlah plasenta previa di Bagian Obstetri dan Ginekologi RSUP Prof. R. D. Kandou Manado dalam kurun waktu 1 Januari 2015 sampai 31 Desember 2015 sebanyak 27 kasus plasenta previa dari total 1700 persalinan $(1,59 \%)$.

Tabel 1 memperlihatkan frekuensi terbanyak pada usia lebih dari dan sama dengan 35 tahun sebanyak 13 kasus atau sekitar $48,1 \%$.

Tabel 1. Distribusi Plasenta Previa Berdasarkan Usia

\begin{tabular}{ccc}
\hline Paritas & $\mathbf{N}$ & $\mathbf{\%}$ \\
\hline 1 & 3 & $11,1 \%$ \\
$2-4$ & 20 & $74,1 \%$ \\
$\geq 5$ & 4 & $14,8 \%$ \\
Jumlah & 27 & $100 \%$ \\
\hline
\end{tabular}

Dari Tabel 2 didapatkan frekuensi terbanyak berdasarkan paritas pada wanita dengan paritas 2-4 yaitu sebanyak 20 kasus $(74,1 \%)$

Tabel 2. Distribusi Plasenta Previa Berdasarkan Paritas Pasien

\begin{tabular}{ccc}
\hline Usia & $\mathbf{N}$ & $\mathbf{\%}$ \\
\hline$\leq 24$ & 2 & $7,4 \%$ \\
$25-34$ & 12 & $44,4 \%$ \\
$\geq 35$ & 13 & $48,1 \%$ \\
Jumlah & 27 & $100 \%$ \\
\hline
\end{tabular}

Dari Tabel 3 dapat dilihat frekuensi plasenta previa yang mempunyai riwayat 
sectio caesarea (SC) sebanyak 7 kasus $(25,9 \%)$.

Tabel 3. Distribusi plasenta previa berdasarkan riwayat $\mathrm{SC}$

\begin{tabular}{ccc}
\hline Riwayat SC & $\mathbf{N}$ & $\mathbf{\%}$ \\
\hline Ya & 7 & $25,9 \%$ \\
Tidak & 20 & $74,1 \%$ \\
Jumlah & 27 & $100 \%$ \\
\hline
\end{tabular}

Dari hasil Tabel 4 dapat dilihat frekuensi terbanyak pada tatalaksana aktif yaitu sebanyak 17 kasus atau sekitar $63 \%$.

Tabel 4. Distribusi plasenta previa berdasarkan tatalaksana

\begin{tabular}{ccc}
\hline Tatalaksana & N & \% \\
\hline Aktif & 17 & $63 \%$ \\
Ekspektatif & 10 & $37 \%$ \\
Jumlah & 27 & $100 \%$ \\
\hline
\end{tabular}

Dari hasil Tabel 5 dapat dilihat frekuensi terbanyak ialah plasenta previa totalis yaitu sebanyak 24 kasus atau sekitar $88,9 \%$.

Tabel 5. Distribusi plasenta previa berdasarkan klasifikasi plasenta previa

\begin{tabular}{ccc}
\hline Klasifikasi & $\mathbf{N}$ & $\mathbf{\%}$ \\
\hline Totalis & 24 & $88,9 \%$ \\
Lateralis & 1 & $3,7 \%$ \\
Marginalis & 0 & 0 \\
Letak Rendah & 2 & $7,4 \%$ \\
Jumlah & 27 & $100 \%$ \\
\hline
\end{tabular}

Dari hasil Tabel 6 dapat dilihat frekuensi terbanyak ialah usia kehamilan aterm yaitu sebanyak 15 kasus $(55,6 \%)$.

Tabel 6. Distribusi plasenta previa berdasarkan usia kehamilan

\begin{tabular}{ccc}
\hline Usia kehamilan & $\mathbf{N}$ & $\mathbf{\%}$ \\
\hline Aterm & 15 & $55,6 \%$ \\
Preterm & 12 & $44,4 \%$ \\
Jumlah & 27 & $100 \%$ \\
\hline
\end{tabular}

Dari hasil Tabel 7 dapat dilihat semua persalinan pada plasenta previa menggunakan cara SCTP.
Tabel 7. Distribusi plasenta previa berdasarkan cara persalinan

\begin{tabular}{ccc}
\hline Cara persalinan & $\mathbf{N}$ & $\mathbf{\%}$ \\
\hline SCTP & 27 & $100 \%$ \\
Pervaginam & 0 & $0 \%$ \\
Jumlah & 27 & $100 \%$ \\
\hline
\end{tabular}

Dari hasil Tabel 8 dapat dilihat frekuensi indikasi persalinan terbanyak ialah inpartu sebanyak 26 kasus $(96,3 \%)$.

Tabel 8. Distribusi plasenta previa berdasarkan indikasi persalinan

\begin{tabular}{ccc}
\hline Indikasi persalinan & $\mathbf{N}$ & $\mathbf{\%}$ \\
\hline Inpartu & 26 & $96,3 \%$ \\
IUFD & 1 & $3,7 \%$ \\
Jumlah & 27 & $100 \%$ \\
\hline
\end{tabular}

Dari hasil Tabel 9 dapat dilihat penyulit persalinan terbanyak ialah preeklampsia yaitu 3 kasus $(11,1 \%)$.

Tabel 9. Distribusi plasenta previa berdasarkan penyulit persalinan

\begin{tabular}{ccc}
\hline Penyulit persalinan & N & \% \\
\hline Akreta & 2 & $7,4 \%$ \\
Preeklampsia & 3 & $11,1 \%$ \\
\hline
\end{tabular}

Dari hasil Tabel 10 dapat dilihat frekuensi terbanyak ialah luaran bayi lahir hidup yaitu sebanyak 26 kasus (96,3\%).

Tabel 10. Distribusi plasenta previa berdasarkan luaran bayi

\begin{tabular}{ccc}
\hline Luaran bayi & N & \% \\
\hline Lahir hidup & 26 & $96,3 \%$ \\
Lahir mati & 1 & $3,7 \%$ \\
Jumlah & 27 & $100 \%$ \\
\hline
\end{tabular}

\section{BAHASAN}

Berdasarkan penelitian yang telah dilakukan sejak November 2016 di bagian Obstetri dan Ginekologi RSUP Prof. Dr. R. D. Kandou Manado, ditemukan 27 kasus plasenta previa dari total 1700 persalinan atau sekitar 1,59 \% pada periode 1 Januari 2015 - 31 Desember 2015.

Pada Januari 2015 sampai Desember 2015 di Bagian Obstetri dan Ginekologi RSUP Prof. R. D. Kandou Manado pada 
Tabel 1 ditemukan Plasenta Previa terbanyak pada usia lebih dari dan sama dengan 35 tahun sebanyak 13 kasus atau sekitar 48,1\%, kedua pada usia 25-34 tahun sebanyak 12 kasus atau sebanyak 44,4\%, dan pada terakhir usia kurang dari dan sama dengan 24 tahun sebanyak 2 kasus atau sekitar 7,4\%. Dari penelitian yang telah dilakukan sebelumnya, prevalensi plasenta previa dalam kelompok usia lebih dari sama dengan 35 tahun lebih tinggi dibandingkan usia kurang dari 35 tahun. ${ }^{12}$

Pada Tabel 2 berdasarkan paritas, frekuensi tertinggi terdapat pada wanita dengan paritas 2-4 yaitu sebanyak 20 kasus atau sekitar $74,1 \%$, kemudian pada wanita dengan paritas lebih dari dan sama dengan 5 yaitu sebanyak 4 kasus atau sekitar $14,8 \%$, dan terakhir pada wanita primipara yaitu sebanyak 3 kasus atau sekitar 11,1\%. Berdasarkan penelitian sebelumnya, disebutkan bahwa wanita dengan multiparitas mempunyai peluang lebih besar untuk mengalami plasenta previa dibandingkan wanita dengan primipara. ${ }^{4,12}$ Karena dalam kehamilan, plasenta cenderung mencari jaringan endometrium yang sehat untuk berimplantasi. Pada kehamilan pertama, fundus merupakan tempat yang subur dan tempat favorit untuk plasenta berimplantasi, tetapi seiring bertambahnya frekuensi kehamilan, kesuburan pada fundus akan semakin berkurang. Hal ini membuat plasenta mencari tempat lain untuk berimplantasi dan cenderung ke bagian bawah rahim. ${ }^{13}$

Dari hasil Tabel 3 ditemukan plasenta previa yang mempunyai riwayat SC yaitu sebanyak 7 kasus dari total 27 kasus atau sekitar 25,9\%. Hal ini tidak sesuai dengan teori yang menyebutkan bahwa cacat bekas $\mathrm{SC}$ berperan dalam proses peradangan dan kejadian atrofi di endometrium dan berperan menaikkan insiden plasenta previa dua sampai tiga kali. ${ }^{4}$ Karena bukan hanya bekas SC, faktor lain seperti multipara juga berperan dalam meningkatkan resiko plasenta previa., ${ }^{4,12}$

Dari hasil Tabel 4 ditemukan frekuensi terbanyak pada plasenta previa yang mendapatkan tatalaksana aktif yaitu sebanyak 17 kasus atau sebanyak 63\%, dan frekuensi terendah pada plasenta previa yang mendapatkan tatalaksana ekspektatif yaitu sebanyak 10 kasus atau sekitar $37 \%$. Dalam penelitian yang dilakukan di Kanada, disebutkan bahwa tatalaksana aktif lebih sering didapat daripada tatalaksana ekspektatif. ${ }^{14}$ Karena pasien pada pasien dengan plasenta previa sudah terjadi perdarahan aktif sehingga lebih banyak mendapat tatalaksana aktif. ${ }^{15}$

Dari hasil Tabel 5 ditemukan frekuensi terbanyak pada plasenta previa berdasarkan klasifikasi yaitu plasenta previa totalis sebanyak 24 kasus $(88,9 \%)$, diikuti oleh plasenta previa letak rendah sebanyak 2 kasus $(7,4 \%)$, plasenta previa lateralis sebanyak 1 kasus $(3,7 \%)$; tidak ditemukan adanya plasenta previa marginalis. Dalam penelitian yang dilakukan di Italia, plasenta previa totalis menjadi kasus yang paling sering ditemukan. ${ }^{6}$

Dari Tabel 6 didapat frekuensi terbanyak ialah usia kehamilan aterm yaitu sebanyak 15 kasus $(55,6 \%)$, usia kehamilan preterm sebanyak 12 kasus $(44,4 \%)$. Hal ini tidak sesuai dengan teori yang menyebutkan bahwa plasenta previa usia preterm lebih sering terjadi. ${ }^{16,17}$ Karena pasien dengan plasenta previa yang masuk rumah sakit dalam keadaan darurat bila terjadi perdarahan aktif tanpa memandang usia kehamilan dan tidak dapat dipertahankan, langsung mendapatkan tindakan operatif. ${ }^{4,15}$

Dari hasil Tabel 7 ditemukan bahwa semua persalinan pada kasus plasenta previa menggunakan cara SCTP (Sectio Caesarea Transperitoneal Profunda). Pasien dengan semua klasifikasi plasenta previa dalam trimester ketiga yang dideteksi dengan USG transvaginal yang belum ada dilatasi serviks, persalinannya dilakukan melalui SC. ${ }^{4}$ Sectio Caesarea menjadi pilihan dalam tindakan operatif karena plasenta telah menutup jalan lahir sehingga bayi tidak bisa dikeluarkan secara normal. Insisi dilakukan pada abdomen dan dinding uterus agar bayi dapat lahir tanpa terhalang oleh plasenta. ${ }^{18}$

Dari hasil Tabel 8 didapatkan 
frekuensi indikasi persalinan terbanyak ialah inpartu sebanyak 26 kasus $(96,3 \%)$. Terdapat 1 kasus $(3,7 \%)$ lainnya ialah persalinan dengan indikasi IUFD (Intrauterine Fetal Death). Inpartu menjadi indikasi terbanyak karena dalam penanganan pasien dengan plasenta previa, umur kehamilan dipertahankan setua mungkin agar bayi terhindar dari prematuritas. ${ }^{19,4,20}$

Dari Tabel 9, didapat penyulit persalinan terbanyak ialah preeklampsia yaitu 3 kasus $(11,1 \%)$, dan akreta dengan 2 kasus $(7,4 \%)$. Pada penelitian yang dilakukan, didapat 5 kasus dengan 2 jenis penyulit yaitu preeklampsia dan plasenta akreta. ${ }^{4,21}$

Dari hasil Tabel 10 ditemukan frekuensi luaran bayi terbanyak ialah lahir hidup sebanyak 26 kasus (96,3\%) sedangkan lahir mati sebanyak 1 kasus $(3,7 \%)$. Lahir hidup menjadi sering dalam persalinan dengan plasenta previa karena pengawasan yang ketat diberikan pada pasien. ${ }^{4,18}$

\section{SIMPULAN}

Dari hasil penelitian dapat disimpulkan bahwa wanita yang memiliki gejala plasenta previa seperti perdarahan tanpa nyeri agar segera memeriksakan ke Rumah Sakit atau dokter spesialis Obstetri dan Ginekologi untuk mendapatkan penanganan sesegera mungkin.

\section{DAFTAR PUSTAKA}

1. Chapman V. Asuhan Kebidanan Persalinan dan Kelahiran. Jakarta: EGC, 2006.

2. Cunningham FG, et al. Obstetri Williams Vol. 1 (23rd ed). Jakarta: EGC, 2012; p. 392.

3. Kemenkes RI. Infodatin. Edisi Mother's Day. Jakarta. 2014. Available from: http://www.depkes.go.id/download.p hp\%3Ffile\%3Ddownload/pusdatin/ infodatin/infodatinibu.pdf\&ved=0ahUKEwj1iu r9gfOAhWBqpQKHQpeCTcQFgg ZMAA\&usg=AFQjCNFtB3UlIKvW hQNW8moSJqabIfojjQ\&sig2=doxlJ GIJJhmf78FHXSOBXw

4. Bari AS. Ilmu Kebidanan Sarwono
Prawiroharjo (4th ed). Jakarta: Bina Pustaka Sarwono Prawirohardjo, 2008; p. 495-502.

5. Adigun TA, Eyelade O. Choice of anaesthetic technique for delivery of pregnancy complicated by placenta previa in Ibadan. OMICS Publishing Group, 2012.

6. Genovese F, et al. Management and time of delivery in asymptomatic complete placenta previa: a case report and review of literature. OMICS Publishing Group; 2012.

7. Kaur B, Dhar T, Sohi I. Incidence, risk factors and neonatal outcomes of placenta previa presenting as antepartum hemorrhage in Tertiary Care Centre of North India. International Journal of Basic and Applied Medical Sciences; 2015.

8. Rangaswamy $M$, Govindaraju, $K$. Fetomaternal outcome in placenta previa - a retrospective study in teaching hospital. Int $\mathbf{J}$ Reprod Contracept Obstet Gynecol. 2016;5

9. Lal AK, Hibbard JU. Placenta previa: an outcome-based cohort study in a contemporary obstetric population. Archives of Gynecology and Obstetrics. 2015;292:299.

10. Yusad Y. Gambaran riwayat obstetri (persalinan) ibu yang mengalami plasenta previa di RSU Dr. Pirngadi Medan. Medan: Universitas Sumatera Utara; 2011.

11. Cunningham FG, et al. Williams Obstetrics (24th ed). McGraw-Hill Education, 2014; p. 799-804.

12. Trianingsih I., et al. Faktor-faktor yang berpengaruh pada timbulnya kejadian placenta previa. Jurnal Kedokteran Yarsi. 2015;23(2):103-13.

13. Sumpraja, et a;. Capaian MDGS terkendala kasus kematian ibu. 2011. [cited 27 November 2016]. Availble from: http://nad.bkkbn.go.id

14. Oppenheimer $\mathbf{L}$, et al. Diagnosis and management of placenta previa. SOGC Clinical Practice Guideline. Canada, 2007.

15. Daflapurkar SB. High risk cases in obstetrics. Jaypee Brothers Medical Publishers India, 2014.

16. Kurniawati N, Triyawati L. Pengaruh 
usia dan paritas terhadap kejadian plasenta previa pada ibu hamil trimester III di RSUD dr. Wahidin Sudirohusodo Mojokerto. Bojonegoro: Akademi Kebidanan Pemerintah Kab. Bojonegoro; 2013.

17. Joseph KS, D'Alton M. Theoretical and empirical justification for current rates of iatrogenic delivery at late preterm gestation. Blackwell Publishing Canada, 2012.

18. Young B, Nadel A, Kaimal A. Does previa location matter? Surgical morbidity associated with location of a placenta previa. Journal of Perinatology. 2014.

19. Honda M, Matsunaga S, Era S, Takai Y, Baba K, Seki H. Intrapartum antidisseminated intravascular coagulation therapy leading to successful vaginal delivery following intrauterine fetal death caused by placental abruption: a case report. Journal of Medical Case Report. 2014;8:461.

20. Van Graas-Hofman R. Effectieve kennisverwerving: de relatie tussen voorkennis. Open Universiteit. Nederland, 2014.

21. Yin $X$, Liu $Y$. Associaion between placenta previa and risk of hypertensive disorders of pregnancy: A meta-analysis based on 7 cohort studies. European Review for Medical and Pharmacological Sciences. 2015. Available from: http://www.europeanreview.org/wp/w p-content/uploads/2146-2152.pdf 